Int. J. Electrochem. Sci., 14 (2019) 9537 - 9551

\title{
Lithium-ion Battery Remaining Useful Life Prediction Based on Exponential Smoothing and Particle Filter
}

\author{
Chaofeng Pan ${ }^{1,2}$, Yao Chen ${ }^{2, *}$, Limei Wang ${ }^{1,2}$, Zhigang $\mathrm{He}^{2}$ \\ ${ }^{1}$ Automotive engineering research institute, Jiangsu University, Jiangsu Province Zhenjiang 212013, \\ China; \\ ${ }^{2}$ College of automotive and traffic engineering, Jiangsu University, Jiangsu Province Zhenjiang \\ 212013, China. \\ *E-mail: chenyao5454@163.com
}

doi: $10.20964 / 2019.10 .15$

Received: 11 June 2019 / Accepted: 23 July 2019 / Published: 30 August 2019

To more accurately predict the remaining useful life of batteries, in this paper, a novel hybrid method that includes a particle filter, exponential smoothing and a capacity degradation model is proposed. First, the parameters of the dynamic model of a lithium-ion battery are estimated by the particle filter to acquire the parameters at each cycle in the estimation phase. Second, these parameters are processed and weighted by exponential smoothing to export the weighted averages of these parameters as the predictive parameters. Finally, the predictive parameters are brought into an empirical capacity degradation model to predict the remaining useful life of the lithium-ion battery. The comparative experiments for predicting the remaining useful life with different end-of-monitoring thresholds are performed to verify the higher accuracy and stability of this hybrid method compared to the pure particle filter method.

Keywords: Lithium-ion battery, Remaining useful life, Exponential smoothing, Particle filter, Parameter estimation.

\section{FULL TEXT}

(C) 2019 The Authors. Published by ESG (www.electrochemsci.org). This article is an open access article distributed under the terms and conditions of the Creative Commons Attribution license (http://creativecommons.org/licenses/by/4.0/). 